BYLAAG

\title{
NATUURWET EN WAARHEID*
}

Inleiding:

Die betekenis van natuurwetenskaplike arbeid lê opgesluit in die "natuurwet" en die "waarheid". Met die natuurwet beheer die natuurwetenskaplike die natuurkragte en verkry hy ' $n$ insig in die natuur wat hom omring. Die waarheid is vir hom die ooreenkoms tussen die natuurgebeure en die verklarende natuurwetenskaplike teorie.

"Waarheid" is egter veel meer as net ooreenkoms tussen feit en teorie. Maar daaroor redeneer natuurwetenskaplikes nie as hulle besig is met hulle eksperimente nie. Hulle hou hulle net by die „essensiële", dit wat regtig saak maak.

Ons stel ons ten doel om vanuit die natuurwetenskap daardie „essensiële" te ontleed. In die natuurwetenskap word soos volg geredeneer: die wêreld om ons is 'n onafhanklike, absolute werklikheid, wat ons kan begryp as ons insien dat die menslike denkwette ooreenstem met die natuurwette omdat hulle die indrukke op ons van buite af beheer. Die natuurwette werk soos ons denke dit begryp.

Dit is hierdie insig, skryf Planck, die beroemde natuurkundige, wat die wetenskaplike aanspoor om die natuurwette na te speur, waardeur die absolute buite ons begryp en beheer kan word. Die nasporing van die wette, wat van toepassing is op hierdie absolute, is die mees verhewene in die lewensarbeid van die natuurwetenskaplikes. ${ }^{9}$ )

Ten einde 'n objektiewe voorstelling van die wêreld om hom te maak, moet die wetenskaplike steeds bereid wees om homself as onbelangrik te beskou. Hy bepaal hom objektief by die natuurgebeure. Sy uitgangspunt is dat die natuur uit die natuur self verklaar is.

Objektiewe ondersoek word eksperimenteel uitgevoer. Hierdeur word subjektiewe denke uitgeskakel en hierom juis die beswaar teen die wysgerige denke waarin die mens met sy vooroordele op die voorgrond tree. Die eksperimentele

\footnotetext{
* Inougurele rede gehou met die aanvaarding van 'n professoraat in Chemie op 21 Oktober 1966.
} 
metode verseker objektiwiteit.

In die eksperiment tree die absolute werklikheid buite die natuurwetenskaplike onafhanklik op. Dit stel die natuurvorser in staat om 'n insig van die meganisme van die werklikheid buite hom te verkry.

Die meganisme van die onafhanklike, absolute werklikheid buite die wetenskaplike word weergegee deur hipoteses, wat die werking van die natuurwette kernagtig beskryf. Wanneer verskillende hipoteses verenig word, tot 'n geheel, word van 'n teorie gespreek. ${ }^{11}$ ) Uit die teorie kan voorspellings gemaak word wat proefondervindelik getoets kan word. Die korrekte uitkoms van die voorspellings dien as bewys vir die waarheid van die teorie.

Bewyse vir die waarheid van natuurwetenskaplike teorieë word in talle opsienbarende tegnologiese ontwikkelinge gevind. Twee van die mees fenominale suksesse, wat die geweldige ontwikkeling van die natuurwetenskap gedurende die twintigste eeu tentoonstel, is die atoombom en die ruimtetuig. Die atoombom is die resultaat van eksperimente wat daarop gerig is om die geheim van kernkrag te ontsluit. Die eerste atoombom is ontwerp kort nadat die Duitse wetenskaplikes Hahn en Strassman in 1939 bewys gelewer het dat neutronbombardement van die uraanatoom lei tot atoomsplyting, waardeur 'n ontsettende hoeveelheid energie vrykom. Die ruimtetuig is die resultaat van eksperimente wat daarop gerig is om die swaartekrag te oorkom met behulp van chemiese energie. Met behulp van 'n gerigte vuurpyl gelaai met 'n kragtige chemiese brandstof, is nou al meer as duisend satelliete in ' $n$ baan om die aarde geplaas.

Die beheersing vain die natuurkragte bewys dat die natuurwetenskap 'n diepe insig in die meganisme van die natuur verkry het. Dit geld nie net vir die lewelose natuur nie, maar ook vir die lewende. In die biologie word geëksperimenteer met komplekse molekulêre samestellings binne die lewendige sel, met behulp waarvan die genetiese faktore beheer kan word. $\left.\left.{ }^{2}\right)^{6}\right)$ Aansprake is al gemaak dat lewendige molekules in die proefbuis berei is. Steeds gaan die soektog voort na die diepste geheimenisse van materie en energie. Hiervan is die ruimteprojekte voorbeelde. Die soektog word gerig op alle natuurgebeure wat waargeneem kan word. Selfs die moontlik- 
heid van die bestaan van lewensvorme op verre planete word ondersoek. ${ }^{1}$ )

\section{'n Gesamentlike wêreldbeskouing:}

Hierdie soektog na die diepste geheimenisse van materie en energie het as doelwit die uitbou van 'n verstaanbare model van die werklikheid. 'n Verstaanbare model is 'n logiese denkpatroon wat ooreenstem met die absolute werklikheid buite ons. Die absolute werklikheid word beheer deur die natuurwette.

Laat ons dit illustreer aan die hand van die atoombom, waarvan die volgende verstaanbare model gegee kan word. ${ }^{3}$ ) Wanneer die uraanatoom, $\mathrm{U}^{235}$, 'n neutron absorbeer splits die kern in twee fragmente van ongelyke massa en word verskeie neutrone vrygestel. Tel ons die res-massas van die produkte bymekaar en vergelyk dit met die res-massas van die oorspronklike kern en neutron, dan is daar 'n ongerymdheid. Die produkte se massas is minder as dié van die reaktante. Die verskil is die massa wat ekwivalent is aan 'n groot hoeveelheid energie. Slegs 'n klein fraksie minder as een persent, van die massa word in energie omgesit, maar die ekwivalensiefaktor volgens die Einsteinse vergelyking is die kwadraat van die ligsnelheid, wat 'n baie groot getal is, sodat 'n geweldige hoeveelheid energie vry kom. Indien die grootte en vorm van die uraan sodanig is dat die meeste neutrone kan ontsnap voordat ' $n$ ander uraankern getref kan word, sal die reaksie hom nie self kan onderhou nie. In 'n groot genoeg stuk $\mathbf{U}^{235}$ sal die neutrone ander uraankerns tref voordat hulle kan ontsnap. Die neutrone neem dan so vinnig toe dat 'n geweldige ontploffing volg.

Die kondisie dat die stuk uraan „ontplof" is dat die kernreaksie oor so 'n kritiese ruimte saamgedring word dat elke uraanatoom splits. Letterlik elke atoom uraan verander in energie. Die omsetting van massa in energie kan met die Einsteinse wet en die wette van die termodinamika bereken word. Hierdie wette word gebruik wanneer die kritiese hoeveelhede bereken word wat die hele massa uraan sal laat ontplof in die atoombom.

In hierdie berekenings pas die natuurwetenskaplike die natuurwette toe op ' $n$ model wat as ' $n$ algemeen-geldende werk- 
likheid agter die natuurgebeure in sy denke gesien word. In sy denke maak hy hom los van die onmiddellik waarneembare..$^{15}$ ) Hy dring agter die werklikheid in om 'n verborge werklikheid te sien. Hierdie verborge werklikheid beheer hy deur die natuurwette.

Die algemeen-geldende werklikheid word 'n gesamentlike wêreldbeskouing. „Ons het te doen met 'n onbewuste en 'n heimlike uitbreiding van die resultate, dit is, feite en metodes van afsonderlike ondersoeke, tot 'n skynbare gesamentlike wêreldbeskouing", aldus die fisici Van der Merwe en Verleger. $\left.{ }^{13}\right)$ Die hele werklikheid word ingesluit. Dit is 'n wêreldbeskouing waarin die outonome rede die natuur uit die natuur self verklaar. Die rede word verhef tot die oorsprong en ordeningsmag van die absolute werklikheid.

Dit klink geweldige woorde in wysgerige ore, maar dit is geen oordrywing nie. In die natuurwetenskaplike handboeke en vaktydskrifte word die rede as die oorsprong of die ordeningsmag van die werklikheid veronderstel. 'n Skepper, 'n skepping en 'n skeppingsorde is daar nie ter sake nie. Die skeppingsgedagte word in die moderne natuurwetenskap eenvoudig nie vermeld nie.

Aan die neutrale universiteite in ons land is daar vele wat meen dat dit ook nie saak maak nie. In die natuurwetenskap waarin objektiwiteit gewaarborg word deur die eksperiment, word die natuur uit die natuur self, verklaar. Die natuurwetenskaplike teorie, gesteun deur die eksperiment, moet eenvoudig aanvaar word.

Die meeste gelowige wetenskaplikes aanvaar dit dan ook so en kom tot 'n gesamentlike wêreldbeskouing waarin die Christelike beskouing versoen word met die moderne natuurwetenskap. Hierdic versoeningspoging wil ons nou ondersoek vanuit die natuurwetenskap self. Ons ondersoek behels die soek na antwoorde op twee vrae: Ten eerste: Watter betekenis heg die natuurwetenskap aan die natuurwet? Dit is noodsaaklik om dié vraag te beantwoord omdat hiermee die meganisme geskep word wat dit onnodig maak om met 'n Skepper rekening te hou.

Ten tweede: watter betekenis heg die natuurwetenskap aan die ontstaan van die lewensvorms en van die mens? Veral die beskouing oor die ontstaan van die mens is belangrik vir die poging tot versoening. 


\section{Die natuurwetenskaplike betekenis van die natuurwet:}

As 'n voorbeeld van hoe die natuurwetenskaplike tot 'n natuurwet kom en hoe hy hom van die onmiddellik waarneembare losmaak om tot 'n algemeen geldende werklikheid te kom, ${ }^{15}$ ) is daar seker geen geskikter model as die ondersoek van die planetêre beweging deur Galileo, Kepler, Newton e.a. nie. Met reg kan Galileo die vader van die eksperimentele metode genoem word. Met behulp van 'n teleskoop en 'n tydspendule het hy die hoeke van die planetestande oor groot tydsperiodes gemeet. Deur herhaalde eksperimente - en dit is nodig om dit te beklemtoon - word 'n insig verkry. Die probleem word opgelos toe Galileo raaksien dat 'n model die gegewens verstaanbaar maak. Die ingewikkelde planetêre beweging kan dan in eenvoudige onderdele gesplits word.

Daar is vir eers die beweging van die planeet om die son, met 'n konstante snelheid, in 'n sirkelbaan. Daar is verder die aantrekkingskrag tussen die twee hemelliggame volgens die swaartekragwet. Die balans tussen die swaartekragwerking en die middelpuntvliedende werking hou die planeet in sy baan.

Let op dat met die swaartekragwet nou 'n funksionele verband gelê is tussen die onderdele van die model. ${ }^{16}$ ) Saamvoeging van die onderdele rekonstrueer die hele werklikheid van die sonnestelsel. Bevestiging vir die rekonstruksie word gevind in die welslae van die voorspellings van son- en maanverduisteringe. Vandag dien ook die welslae van satellietprojekte as bevestiging van hierdie bewegingsmodel.

Dit is belangrik om op te merk dat Galileo, Kepler, Newton, e.a. wat die planetêre bewegings ondersoek het, dit nie nodig vind om die oorsprong van die sonnestelsel of van die swaartekrag te verklaar nie. Hulle aanvaar dit so, want die wêreld om hulle is 'n onafhanklike, absolute werklikheid. Daarvoor is nie verdere verklaring nodig nie. Die planetêre beweging gaan vanself al die eeue só voort. Wiskundig word dié uitgangspunt in berekening gebring deur die eenparige beweging in 'n sirkelvormige baan. Die diepere oorsaak vir die kragte wat die planete in hulle bane hou, is nie ter sake nie. Dit is die "hoe" en nie die "waarom" nie, wat vir die wetenskap van betekenis is. ${ }^{16}$ )

"Natuurwet" is eers gebruik in die sin van „bevel" wat verband hou met die opvatting dat 'n Absolute Heerser oor die 
Heelal, deur middel van vaste wette van die Skepping af, regeer. Hierdie opvatting leef nog in die taalgebruik waar daar gespreek word van die natuur van wette "gehoorsaam".

Die natuurwet word egter nou meer gesien in die sin van „verklaring". In die natuurwetenskaplike sin word 'n natuurwet beskou as ' $n$ aan die natuur inherente funksionele verband, wat egter statisties van aard is. Dit is statisties van aard omdat ons metinge afwykinge vertoon. Daar is bv. in die sonnestelsel sekere onreëlmatighede in die konsentriese planetêre bane opgemerk. 'n Natuurwet wat afwykings vertoon is nie meer heeltemal seker nie. Daarom is te begrype dat Newton wat aan 'n kousale natuurwet vasgehou het - d.w.s. 'n oorsaakgevolg-wetmatigheid gehandhaaf het - van mening was dat ' $n$ goddelike mag van tyd tot tyd moes ingryp om die sonnestelsel weer in ewewig te bring en die hemelliggame te vrywaar van botsings.

Die meganika van Newton was 'n idealisering waarin aangeneem word dat ons die natuurverskynsels kan ondersoek sonder om ons self te betrek. ${ }^{14}$ ) Hierin is daar deur die moderne kwantummeganika 'n ommekeer gebring. Nuwe feite moes onder oë gesien word, waardeur dit vanaf die derde dekade van hierdie eeu duidelik geword het dat 'n kontinue natuurbeeld nie strook met die feite nie. Nie net materie is diskontinu nie - d.w.s. bestaan uit atome - maar energie is ook diskontinu. 'n Energie-atoom word 'n kwantum genoem. Maar nou kom nog by dat die materie-atome ook golfeienskappe besit.

Hierdie nuwe meganika, die kwantummeganika bring 'n hele ommekeer waardeur die onsekerheidsbeginsel sy intrede mak. Die onsekerheid spruit uit die poging om twee modelle wat eintlik bots, aan dieselfde fisiese entiteit, bv. 'n elektron, toe te ken.16) Die golfmodel is ontleen an die basiese begrip van 'n kontinue energieveld. Die deeltjie-model, daarenteen, is ontleen aan die begrip van ondeelbare materie-eenhede, wat fundamenteel diskontinu d.w.s. atomies is. ${ }^{8}$ ) Wanneer ons nou aan die deeltjie 'n golfeienskap gee, ken ons 'n uitgestrektheid daaraan toe, wat noodwendig die posisie van die deeltjie onbepaald laat. Om sy posisie te bepaal word opmekaarplasing van golwe met verskillende frekwensies vereis. Daardeur word weer die deeltjie se momentum onseker. Die resultaat is dat die waarskynlikheidsrekening gebruik word om te bereken in 
watter gebied die deeltjie is.

'n Baie belangrike aspek is dat wat onseker is vir 'n enkele elektron, met groot noukeurigheid voorspel kan word vir 'n groot aantal elektrone of ander atomêre deeltjies..$^{16}$ ) Hierdeur word die statistiese wet vir groot getalle deeltjies 'n vername element van natuurbeskrywing. 'n Sisteem van partikels gaan spontaan oor van 'n toestand van lae waarskynlikheid na een van hoë waarskynlikheid. Die potensiaal vir die verandering is die waarskynlikheid vir die verandering. ${ }^{2}$ )

Dat die potensiaal vir ' $n$ verandering gelyk is aan die waarskynlikheid vir die verandering dra eintlik net betekenis in 'n geslote sisteem van deeltjies wat nie vér van hulle ewewigstoestand is nie. In die natuurwetenskaplike denke word dit egter geprojekteer om agter die werklikheid in te dring. Die natuurverskynsels word nou as waarskynlikhede gesien.

Dit is 'n nuwe natuurwet. Die natuurverskynsel wat plaasvind, vind plaas omdat dit waarskynliker is as die een wat nie plaasvind nie. Die waarskynlikste gebeurtenis vind plaas, en dit vind spontaan plaas. Die dryfkrag wat in 'n sisteem werksaam is, is sy waarskynlikheid.

As antwoord op die vraag na die betekenis van die natuurwet vir die natuurwetenskap, vind ons die antwoord dat dit 'n statistiese funksionele verband is, wat die algemeen-geldende werklikheid beheer. Die algemeen-geldende werklikheid is eintlik die verborge werklikheid agter die eksperimente.

Hierdie verborge werklikheid is vir die natuurwetenskaplike net so reëel as die waarneembare self. So splits die astronoom die beweging van die maan op in 'n gedeelte bepaal deur die aantrekkingskrag van die aarde en 'n gedeelte bepaal deur die aantrekkingskrag van die son. Nie een van hierdie gedeeltelike bewegings word waargeneem nie. Hulle is teoretiese konstruksies. Nietemin word aan hulle werklikheid nie getwyfel nie.

Hierdie werklikheid sluit vir die natuurwetenskaplike alle natuurverskynsels in - leweloos en lewendig. Die ontstaan van organismetipes in die biologie word gesien vanuit die oogpunt van hulle bestaansmoontlikhede.

Hierdie beskouing word ook na die mens uitgebrei. Omdat die mens ook 'n natuurverskynsel is, word sy ontstaan toegeskryf aan gunstige waarskynlikheidsfaktore. Daar bestaan immers vir die natuurwetenskap, wat die mens op die 
agtergrond stel - ten einde nie deur sy vooroordele in die natuurwetenskaplike denke belas wees nie - geen ander uitweg nie.

Dit is juis in hierdie opsig dat die vraag na die betekenis, vir die natuurwetenskap, van die toevallige ontstaan van die mens, uit 'n dierlike voorouer, so uiters belangrik is vir die Christelike beskouing, waarvolgens die mens bestem is as beelddraer van die Skepper.

Wanneer die natuurwetenskaplike beskouing van die bestaansmoontlikhede van die organismetipes nagegaan word, word die terrein van die molekulêre biologie betree.

\section{Molekulêrbiologiese beskouing van bestaansmoontlikhede:}

In die moderne natuurwetenskap word die molekule as die fundamentele eenheid van die biologiese ondersoek gesien en nie meer die sel nie. Dit is 'n aksentverskuiwing, waardeur die biologie eintlik 'n molekulêre of chemiese wetenskap word.6)

Hierdie beskouing spruit voort uit verskeie oorweginge. Alle lewende organismes is opgebou uit presies dieselfde chemiese elemente as wat in die lewelose natuur voorkom. Dit word beklemtoon dat alle lewende organismes ondanks hulle makro-morfologiese verskille ten opsigte van die biochemiese prosesse só eenders is dat alle lewendige organismes - plant en dier - eintlik as 'n biotiese eenheid gesien kan word.5) Opmerklik is dit dat alle lewende selle vernamelik opgebou is uit proteien-molekules, met kenmerkende aminosuurstrukture, en nukleïensure wat weer gekarakteriseer word deur 'n besondere basiese binnestruktuur.

Dit is ingewikkelde strukture. Die proteïenmolekules se gewigte is duisende kere meer as die van die eenvoudige watermolekule en die nukleïensuur-molekules weer miljoene keer soveel as 'n watermolekule. Die ingewikkeldheid word veel verminder deur te soek na die onderdele waaruit die geheel weer gekonstrueer kan word, op tipiese natuurwetenskaplike wyse.

Dit is van belang om nou op die resultate van twee baie belangrike eksperimente te let. Ten eerste is bevind dat wanneer 'n mengsel van eenvoudige gasse soos ammoniak, metaan, koolstofmonoksied, waterstof en waterdamp met ultra- 
violetlig bestraal word, spontaan, d.w.s. vanself, aminosure ontstaan. ${ }^{7}$ ) Weliswaar ontstaan nie proteïenmolekules nie, maar die spontane ontstaan van die boustene van proteïenmolekules nou ook 'n waarskynlikheid, d.w.s. bestaansmoontlikheid. Die waarskynlikheid is immers die potensiaal vir die gebeurtenis. Proteïenmolekules kan dus vanself uit lewende molekules ontstaan het.

In die tweede eksperiment het ons te doen met die afbraak van lewendige selle na molekules. Uit sekere tabakvirus-selle is kenmerkende kristalle geïsoleer. Hierdie kristalle word weer met 'n tabakekstrak in aanraking gebring en bevind dat meer kristalle uitgekristalliseer kan word. ${ }^{6}$ ) Die vermeerdering van die kristalle word nou as „voortplanting gesien. Kristalle is tipiese chemiese strukture. Ons het dus te doen met „lewendige chemiese strukture". Hulle is biologiese struktuureenhede, maar ook chemiese strukture.

Die argument is nou wel verswak daardeur dat hierdie kristalle op hulle eie nie kan voortplant nie, dog alleen wanneer dit weer met die tabakekstrak in aanraking gebring word, maar die natuurwetenskap negeer die argument dat hierdie kristalle as lewelose brokstukke beskou kan word wat weer opgeneem word in 'n lewendige sisteem. Nee, die resultate van albei eksperimente word verenig. Die bewyskrag lê in die kombinasie van die resultate, nl. biologiese struktuureenhede is chemiese strukture, waarvan die bestaansmoontlikhede juis die potensiaal is vir hulle ontstaan.

Op kernagtige wyse stel die Roomse paleontoloog, De Chardin, wat dikwels in natuurwetenskaplike boeke aangehaal word, die biologiese-molekulêre evolusie voor: „Net soos die mens vir die paleontoloog anatomies voortvloei uit die massa soogdiere wat hom voorafgaan, so smelt, die sel, in dieselfde historiese reeks saam met die wêreld van chemiese strukture en konvergeer tot die molekule".4) Die moderne natuurwetenskap verwag om bewyse te vind vir die toevallige ontstaan van lewe op sekere planete waar sodanige biologies-molekulêre verskynsels moontlik gemaak word deur gunstige faktore. In die ruimteprojekte word hiermee rekening gehou. Daar is gegewens wat as bewys interpreteer word vir die bestaan van primitiewe lewensvorms op die aarde sowat 3,000 miljoen jaar gelede, toe waarskynlik 'n atmosfeer van dieselfde gasse (wat in die eerste eksperiment genoem is) op die oer-aardopper- 
vlakte bestraal is, deur die ultravioletstrale van die son. Hierdie ultravioletstrale moes baie kragtig gewees het toe die osoon-laang, wat die huidige aarde daarteen beskerm, seker afwesig moes gewees het!

Dit is opmerklik dat natuurwetenskaplike denke geen oog het vir bestemming in die natuur nie. Die natuurgebeure vind spontaan plaas d.i. vind vanself plaas. Die potensiaal om plaas te vind is die waarskynlikheid om te gebeur. Die molekulêre kragte werk lottoevallig. Bestemming bestaan nie in die natuur nie want alles vind toevallig plaas.

Voortplanting en erflikheid word ook volgens 'n waarskynlikheidspatroon deur die biologies-molekulêre teorie verklaar. Die oordrag van die erflikheidsfaktore word beheer deur die meestermolekule, die DNS-molekule (deoksieribonukleïensuur). Hierdie molekule dra as 'n integrale deel van sy chemiese struktuur 'n stel gekodifiseerde instruksies vir die volle beheer van die groei en die aard van die sel. Die DNS-molekule besit die essensiële vermoë om getrou volgens 'n vaste patroon te dupliseer. Dit vorm die grondslag vir die reëlmatige en sekure deling van die selkern sodat die twee dogterselle presies soos die moedersel tevoorskyn tree. Die verdeling van die DNS-molekule in twee dogtermolekules, word voorgestel as die ontkoppeling van die dubbele spiraal (van suikerfosfaat) van die DNS-molekule. So word 'n meganiese beeldverklaring vir die tweedeling verkry. $\left.{ }^{2}\right)^{6}$ )

Wysiging van die dogtermolekules kan egter deur 'n klein, maar kritiese molekulêre verandering in die base-pare binne die DNS-molekule bewerkstellig word. Hierdeur word die erflikheidskode verander. Vir so 'n verandering of mutasie bestaan daar 'n moontlikheid. Faktore wat die chemiese konsentrasie van die gewysigde dogtermolekules verhoog, word as gunstig vir die ontstaan van 'n nuwe organisme-tipe beskou.

Hierdie gunstige faktore word in die genetika gesoek. $\left.{ }^{2}\right)^{6}$ ) In die chemie kan hulle nooit gevind word nie omdat dáár vanuit 'n termodinamiese, kinetiese en kwantummeganiese standpunt geredeneer word wat met biologiese faktore geen verband het nie. Die molekules waarmee die chemie werk is almal leweloos. Dit is egter geen probleem nie, omdat dit as 'n natuurwet beskou word dat die waarskynlikheid die potensiaal vir die transformasie is. Die waarskynlikheid of moontlikheid bestaan buitendien want die betrokke organismetipe 
word gevind.

Die betekenis wat die molekulêre biologie aan die ontstaan van lewensvorms heg kan beskryf word as die universaliteit van die genetiese kode. Die „kodeletters" vir die bou van die aminosuur-boustene vir die proteïenmolekules wat bakteriese sisteme kenmerk is bv. dieselfde as vir soogdiere. Ontaarding van die genetiese kode begunstig die oorlewing van organisme-tipes.6) Die evolusionistiese stamboom is daarom gegrond op die universaliteit van die genetiese kode.

\section{Pogings tot versoening:}

Laat ons nou sien hoe 'n gelowige natuurwetenskaplike wat die moderne natuurwetenskaplike teorie handhaaf en tegelyk ook glo in 'n Skepper, poog om versoening te bring. Aan die een kant het ons die uitgangspunt dat die organismetipes vanself volgens die waarskynlikheidswette te voorskyn tree. Aan die ander kant het ons die geloof in 'n Almagtige Vader wat alles formeer volgens ' $n$ skeppingsplan en in stand hou.

Volgens die natuurwetenskaplike uitgangspunt dat die wêreld om hom 'n onafhanklike, absolute werklikheid buite hom is, kan die geloofstandpunt dus nie in die wetenskap ingedra word nie. Ten einde versoening te probeer bewerk, word daarom die natuurwetenskaplike standpunt in die Christelike beskouing ingedra. Daar word nl. natuurwetenskaplike bewyse vir die Skrifwaarhede geoek. ${ }^{14}$ )

As voorbeeld van die wyse waarop natuurwetenskaplike steun vir die Skrifwaarhede gesoek word verwys ons na die woorde „die aarde bring voort kruipende diere..." wat só gesien word dat dit waarskynlik is dat God by die skepping van die eerste lewensvorms gebruik gemaak het van aanwesige verbindings. Dit pas aan by die biologies-molekulêre voorstelling. Die Skepping word dan gesien as 'n ontvouing van die potensies wat die Skepper in die geskapene gelê het, langs 'n weg waarin die molekulêre biologiese waarskynlikhede verwesenlik word. Dit word só deur Lever gestel: „Die evolusieproses kan daarom in 'n natuurlike proses wees, maar dan van so 'n dergelike gekompliseerdheid en onwaarskynlikheid dat slegs wanneer God, wat al die prossese in die natuur lei, planmatig alle faktore op 'n bepaalde wyse kombineer, die nuwe tipe te voorskyn kom".5) 
Daar word op gewys dat die planmatigheid van die Skepping dan begryplik word deur die beskouing dat die onwaar. skynlike prosesse deur God gelei word. Allerlei faktore buite om Gods wil, kan dan nie die Skeppingsplan wysig nie, sodat die Skeppingsplan vas bly.5)

Nie alleen word die planmatigheid van die Skepping begryplik uit die wyse waarop God die onwaarskynlike molekulêr-biologiese prosesse lei nie, maar ook die skielikheid van die tipe ontwikkeling word verstaanbaar. Hier is 'n poging om die skepping van die tipes „,volgens hulle aard" deur diskontinuïteite in die leiding van die waarskynlikhede te sien. Die skaarsheid van paleontologiese vondse word dan duidelik.

Hoewel ons waardering het vir die poging om so die feite in die lig van die Christelike geloofsoortuiging te plaas, bly twee grondvraagstukke nog steeds onopgelos. Die eerste is dat die blinde natuurkragte wat deur waarskynlikhede werk, aan die een kant en God wat die waarskynlikhede lei, aan die ander kant, dan per slot van rekening dieselfde is. Die tweede is dat die mens wat van die geslag van God is, deur sy molekulêre biologiese verbondenheid, dan maar eintlik nog van dierlike afkoms is.

Die slotsom kan nie ontwyk word nie, dat die natuurbeeld van die moderne natuurwetenskap, soos dit in die molekulêre biologie vergestalt is, nie versoen kan word met die Christelike standpunt nie.

Wat is dan die Christelike standpunt?

Vir eers kan die geloof in die Skrifwaarheid nie natuurwetenskaplik bewys word nie. Nie die natuurwetenskap nie, maar die geloof bepaal wat geloof is.

„Die geloof is die bewys van die dinge wat nie gesien kan word nie" (Heb. 11).

Wanneer die Christelike natuurwetenskaplike die wetenskap beoefen dan is dit nie sy metode wat anders is as dié van die ongelowige nie. Hy gebruik dieselfde induktiewe eksperimentele metode om die wetmatighede na te spoor. ${ }^{11}$ ) Hy maak ook van teoretiese modelle gebruik om die wetmatighede oorsigtelik weer te gee, solank as wat hy besig is met waarhede wat die natuurwetenskap by magte is om te kan ondersoek..$^{10}$ )

Hier het ons nou gekom by die essensie van die saak. Die Christelike wetenskaplike plaas hom op die standpunt dat 
die geskape werklikheid, waarvan hy as natuurvorser 'n on losmaaklike deel is, die handwerk van God, as die Absolute, is. Die standpunt dat die natuur buite hom 'n onafhanklike, absolute werklikheid is, wat hy met sy outonome rede kan verklaar, kan hy nie aanvaar nie."1) Hy besef dat hierdie sogenaamde neutrale standpunt nie objektiwiteit kan waarborg nie.

Daarteenoor stel hy dat hy as natuurwetenskaplike objektief is wanneer hy getrou is aan die waarheid..$^{10}$ ) $\mathrm{Hy}$ betoog dat hy nooit nader aan die waarheid staan as wanneer hy hom laat lei deur die Skrifopenbaring, wat "objektief" is omdat dit bo die mens staan. Al is die Woord van God nie 'n wetenskaplike handboek nie, laat dit tog sy lig val op grondwaarhede wat die natuurwetenskap nie by magte is om te kan ondersoek nie.

'n Sodanige beginsel wat die natuurwetenskap nie by magte is om te ondersoek nie is dat God Almagtig die werklikheid absoluut beheer. Die natuurverskynsels vind nie somar vanself plaas nie. Selfs die gesonder verstand kom in opstand daarteen dat waarskynlikheid die potensiaal is vir 'n gebeurtenis om plaas te vind. Stel $u$ voor dat 'n dokter wat die dood van 'n twintigjarige jongman ondersoek, lewensversekeringstabelle naslaan, daarin lees dat elke dag daar een uit elke tienmiljoen twintigjariges sterf, en dan as bevinding gee dat dit vandag nou juis daardie tienmiljoenste is wat vanself doodgegaan het - 'n ondersoek is onnodig! Die verborge dinge is ondeurgrondelik. Daarom betaam dit ons om beskeie te wees en ook as natuurwetenskaplikes te erken dat wat ons begryp maar min is, juis op grond van 'n tweede Skrifbeginsel wat ons noem, nl. dat 'n mens se rede en sinne verduisterd is en dat die natuur in 'n abnormale toestand verkeer as gevolg van die sondeval.

Dit kan as 'n verdere Skrifbeginsel, wat die natuurwetenskaplike nie by magte is om te ondersoek nie, genoem word dat die Almagtige Skepper alles volgens 'n skeppingsplan gewil en volmaak in aansien geroep het. Daar is bestemming. Die skeppingsgebeure is afgesluit en God het gesien dat dit goed is. Die gelowige bioloog soek daarom na die doelmatige verskeidenhede van die grondbouplanne in die organisme-tipes. Hy sien die doelmatigheid van elke organisme-tipe raak. Hy aanvaar die talle eksperimente wat bewys dat die tipes nie 
fundamenteel verander kan word nie. Uit herhaalbare eksperimente alleen kan die wetmatighede afgelei word. Daarom kan die oorsprong van die tipes nie ondersoek word nie, want dit het nét éénmaal gebeur. Die eksperimente toon maar telkens aan dat die tipes konstant bly en slegs in minder belangrike tipe-eienskappe kan verander. Omdat die gelowige bioloog dan insien dat die natuurwetenskap nie by magte is om die ontstaan van die tipes te ondersteun nie, aanvaar hy die Skrifwaarheid dat die ontstaan van die organisme deur skepping ontstaan het. Daarom aanvaar die gelowige bioloog die skepping van die grondtipes wat almal ten volle doelmatig is. Hulle ontstaan nie toevallig in 'n kontinue reeks in 'n stygende lyn van beter aanpassing nie.

Ewe-eens sien die gelowige paleontoloog in dat die ontstaan van die organisme-tipes 'n éénmalige, onherhaalbare gebeurtenis is waardeur hy verhinder word om die eksperimentele metode, gebaseer op talle herhalings, te beoefen. Omdat alleen uit herhaalbare eksperimente die wetmatighede raakgesien kan word, besef hy dat die paleontologie ook nie by magte is om die ontstaan van die organisme-tipes te ondersoek nie. Daarom aanvaar hy ook die Skrifwaarheid dat die organismes as fundamentele tipes geskape is. Daardeur verklaar hy die fossielbevattende lae anders as die moderne natuurwetenskap. Hy sien $\mathrm{nl}$. die fossielbevattende lae nie as 'n geskiedenis van die organismes nie, maar as 'n geskiedenis van die lae self! Laat ons dit illustreer. ${ }^{14}$ ) Die oorgrote meerderheid van fossiele het in die water gelewe. Daar is 'n verrassende ooreenkoms tussen die voorkoms van organismes in diepgeleë sones in die oseane en die voorkoms van fossiele in die aardlae. Fossilering van die organismes in bepaalde sones het gevolg nadat op 'n bepaalde plek en diepte, dié organismes bedek geraak het deur 'n massa van een of ander materiaal. Vinnige bedekking en hoë druk is chemiese vereistes vir fossilering. Oorlewendes kan ontsnap soos bv. die selekantvis, wat in fossielelae gevind is maar vandag nog in die diepwaters gevind word. ${ }^{14}$ )

Die volgende, hoër sone vorm dan weer die bodem op daardie plek. So kan meer lae gevorm word. Die geologie is bekend met geweldige verskuiwings waardeur die seebodem kan styg. Die gevormde lae kan só 'n moerasagtige streek word waarin die fossiele van amfibiese herkoms nog bokant die 
boonste laag seediere gevind kan word. Die moerasagtige streek mag weer sak. Dit kan later ook weer heeltemal landoppervlakte word. Daar is bv. skulpe bo-op berge gevind. ${ }^{12}$ )

Omdat die sones in die diepwater van bo na onder 'n duidelike verandering in die tipe-bouplan openbaar kan die gevormde fossiellae met ' $n$ bepaalde oseaandiepte in verband gebring word. Dit staan reëlreg teen die opvatting dat die fossiellae die geskiedenis van 'n kontinue tipe-ontwikkeling toon.

Die beskouing dat die aanwesige fossieltipes die aardlae se geologiese geskiedenis beskryf, laat reg geskied aan die grondwaarheid dat daar 'n skeppingsplan vir die organismes is en dat daar 'n skeppingsorde is, wat nie deur die natuurwetenskap ondersoek kan word nie. Die Skepping onttrek hom aan elke poging tot natuurwetenskaplike beskrywing.

In besonder is die natuurwetenskap nie by magte om die grondwaarheid van die ontstaan van die volledige mens te ondersoek nie. Eksperimenteel kan die mens nie uit 'n dier ontwikkel word nie. Die ontstaan, uit 'n ouerpaar, van 'n mens wat kan dink, kan voel, 'n gewete besit, kuns kan beoefen, kan geniet, kan liefhê, kan haat, onttrek hom aan elke poging tot natuurwetenskaplike ondersoek. Juis weens sy „objektiewe" benadering heg die natuurwetenskaplike geen betekenis aan die subjektiewe nie. Die mens kan net "dink" en nie ook „voel" nie. In die evolusie van die mens uit 'n dierlike voorouer tree die denke na vore in die vermoë om vuur te maak en klip- en beenwapens doeltreffend te gebruik. Die grootte van die breinholte dien as maatstaf van die gehalte van die denkvermoë. In die dierkundige handboeke van ons tyd word dit as resultaat van die natuurwetenskaplike denke gestel dat die mens van 'n dierlike voorvader toevallig te voorskyn tree. Sy ontstaan is heeltemal onbeplan. Hy het geen bestemming nie en daarom ook geen roeping nie.

In die Christelike wetenskapsbeskouing word die Skrifwaarheid aanvaar dat die mens as van Gods geslag is, geskep om die Skepper te dien met uitnemende gawes van hart en verstand. Die taak wat die mens het om oor die aarde te heers oefen die Christelike natuurwetenskaplike uit in 'n besondere mate in die wetenskaplike denke. Die ongelowige natuurwetenskaplike aanvaar nie doelbewus die roeping om God die Skepper te dien nie, want in sy wetenskaplike teorieë kom hy uit 
by 'n blinde $\mathrm{krag}$, wat as 'n waarskynlikheidswet 'n verborge realiteit beheer. Hoe kan hy 'n roeping hê as hy geen God erken nie?

Hoe erken hy God in sy wetenskaplike denke? Deur nie agter die waarneembare 'n onafhanklike, absolute werklikheid te sien wat toevalsbeheerd is, maar Gód as die Skepper, die Regeerder, die Absolute, te erken.

Dít is die waarheid. En die waarheid maak ons ook in ons denke vry van die misplaaste waarde wat aan die „outonome" rede geheg word.

\section{P.U. vir C.H.O.}

J. A. van den Berg.

\section{BRONNELYS}

1) Ahrens, L. H.: Suid-Afrikaanse Industr. Chemikus (1966), $20,42$.

2) Barrow, G. M.: Physical Chemistry, McGraw-Hill Book Co. 1966 (p. 199, 816).

3) Castellan, G. W.: Physical Chemistry, Addison-Wesley Public Co. Reading (1964), 621-622.

4) de Wit, J. J. D.: A New Critique of the Transformist Principle in Evolutionary Biology (1965), p. 15. Herdruk uit Philosophia Reformata (1964), 29.

5) Lever, J.: Het Creationisme, Intreerede 1952, Vrije Universiteit, Amsterdam, p. 10-22.

6) Martin, R. B.: Introduction to Biophysical Chemistry McGraw-Hill Book Co., New York, 1964, p. 299 e.v.

7) Miller, S. L.: J. American Chem. Soc. (1955), 77, 2351.

8) Moore, W. J.: Physical Chemistry, Longmans Green \& Co. (1963), 481, e.v.

9) Planck: A Scientific Autobiography - aangehaal in Moore W. J., p. 467.

10) Potgieter, F. J. M.: Die Kerkbode, 11 Mei 1949, p. 8.

11) Stoker, H. G.: Beginsels en Metodes in die Wetenskap, Pro RegePers Bpk., Potchefstroom, 1961.

12) Stirton, R. A.: Time, Life and Man, Chapman and Hall, London (1959).

13) van der Merwe, J. H. \& Verleger, H.: Tydskrif vir Wetenskap en Kuns (1953), 13, 1, 125.

14) van der Walt, N. G. S.: Koers (1965), 32, 640.

15) Van Riessen, H.: Christian Perspectives Pella Publish, Pella, Iowa, V.S.A. (1960), p. 37 e.v.

16) Waisman, F.: De Onttroning deur Causaliteit uit: Keerpunten in de Fysica, Aula-Boeken, Antwerpen, 1961. 